\title{
An intrauterine device in the bladder mimicking urinary tract infection
}

\author{
H M Senanayake ${ }^{1}$ and Harshini Fernando ${ }^{2}$
}

(Index words: Two pregnancies after IUD insertion, urolith formation on IUD)

\section{Case report}

A 22-year old woman with three children was admitted with a history of lower abdominal and vaginal pain of 9 months' duration. Pain was felt at the end of micturition and during walking. During this period she had repeated courses of antibiotics for urinary tract infection, but the pain persisted despite laboratory evidence of adequate treatment. When a psychiatry referral was planned in her local hospital she sought admission to the National Hospital of Sri Lanka, where a radiograph showed a copper-T intrauterine device in the lower abdomen. An ultrasound study confirmed this to be in the bladder.

She had had an intrauterine device (IUD) inserted 6 years previously, when her first child was 4 months old. A sharp pain accompanied its introduction and disappeared in a few days. She did not recall any haematuria or other urinary symptoms at the time. Nine months later, she became pregnant, and this was presumed to be due to spontaneous expulsion of the IUD. The pregnancy was uneventful. She had another uneventful pregnancy two years later.

When cystoscopy was done, the IUD with urolith formation around one of the arms and another over the tail was seen lying completely free (Figure). Its removal was completed by extraperitoneal cystostomy after attempts at removal by cystoscopy failed. The patient made an uneventful recovery.

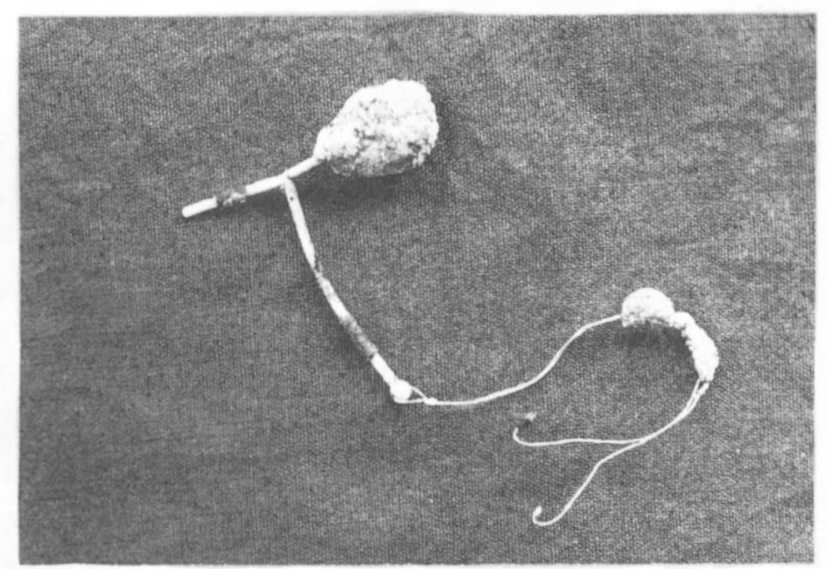

Figure. IUD with urolith formation removed at cystostomy.

\section{Discussion}

Migration of an IUD to the urinary bladder is rare (1). Many reported cases in fact deal with partial perforation (2). In this patient the device was lying completely free in the bladder. This may have contributed to her being free of symptoms for almost 5 years, since a T-shaped IUD would fit the triangular shape of the bladder with minimum disturbance.

An IUD could enter the bladder in one of several ways. First, there could be a direct introduction into the bladder via the uterus. A second method is partial perforation of the uterine wall at insertion, and gradual expulsion into the bladder due to action of the uterus (3). The rather unlikely possibility of direct transurethral insertion has been suggested in one report (4).

Pregnancy should raise suspicion of improper placement, transmigration, or expulsion of an IUD. Localisation during pregnancy is difficult except when the threads are felt, but a lost IUD must be looked for in the placenta and membranes at the time of delivery. If it is not found, expulsion must be confirmed by imaging of the abdomen and pelvis. The small size and softness of the uterus in the early months after childbirth call for great care during IUD insertion (5).

\section{References}

1. Kassab B, Audra P. The migrating intrauterine device. Case report and review of the literature. Contraception, Fertilite, Sexualite 1999; 27: 696-700.

2. Caspi B, Rabinerson D, Appelman Z, Kaplan B. Penetration of the bladder by a perforating intrauterine contraceptive device: a sonographic diagnosis. Ultrasound in Obstetrics and Gynecology 1996; 7: 458-60.

3. Kiilholma P, Makinen J, Vuori J Bjornerem A, Tollan A. Intrauterine device - primary and secondary perforation of the urinary bladder. Acta Obstetricia et Gynecologica Scandinavica 1997; 76: 383-5.

4. Hernandez-Valencia M, Carrillo Pacheco A. Intra-vesical translocation of an intrauterine device, report of a case. Ginecologia y Obstetricia de Mexico. 1998; 66: 290-2.

5. Kiilholma P, Mäkinen J, Mäenpää J. Perforation of the uterus following IUD insertion in the puerperium. Advances in Contraception 1990; 6: 57-61

${ }^{1}$ Senior Lecturer, Department of Obstetrics and Gynaecology, Faculty of Medicine, University of Colombo, and ${ }^{2}$ Resident Physician, National Hospital of Sri Lanka, Colombo 8. (Received 30 August 2001, accepted 19 October 2001. Corresponding author HMS, telephones 071762176 and 075 349567) 